\title{
CONGENITAL ATRESIA OF THE ALIMENTARY TRACT.
}

\author{
BY \\ W. P. H. SHELDON, M.D., M.R.C.P., \\ Medical Registrar, Hospital for Sick Children, Great Ormond Street.
}

In an analysis of the autopsies performed at the Hospital for Sick Children since the beginning of this century, numbering 6,000 in all, congenital atresia of some or other part of the alimentary tract has been found on 28 occasions, and it is on these cases that this report is based. In addition, congenital narrowing without complete obliteration of the lumen has been found in six cases, and a brief account of these is also given. Various other congenital abnormalities closely connected with the development of the intestinal tract, such as obliteration of the common bile duct, abnormalities associated with Meckel's diverticulum, imperforate anus, and unusual formations of the peritoneum, have not been included, being outside the scope of this paper.

The following list shows the number of cases at the various sites of obstruction :-

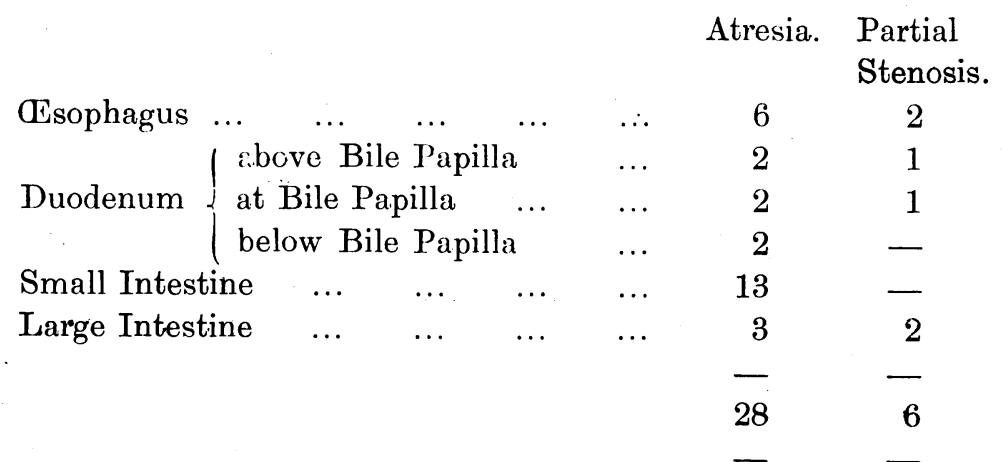

\section{Esophagus.}

The average length of life of the six cases of œophageal atresia was nine days, the extremes being six and thirteen days.

The typical symptoms of this ccndition were shown in each case, and consisted of returning a mixture of food and mucus immediately afte: swallowing. The vomit was in every case returned through the nose as well as the mouth, and was in some cases preceded by a violent fit of coughing, during which the child became cyanosed and seemed in immediate danger of succumbing. Attempts to pass a soft rubber catheter into the stomach were inevitably unsuccessful, obstruction being met with after the tube had been passed four or five inches beyond the lips. Examination of the chest revealed in most cases evidence of bronchitis, and in four cases the temperature was raised until death, reaching in one case $106^{\circ}$. 
In one case bile pigments were found in the vomited material, this being clear evidence of a communication between trachea and the lower end of the œsophagus below the atresia. The filling of the stomach with air during respiration or coughing, which is a further sign of such a communication, was not noted in any of the cases.

The post mortem findings were closely similar in five cases; the esophagus ended blindly, approximately at the level of the bifurcation of the trachea, the proximal portion being considerably dilated. The distal portion of the cesophagus was narrow, and its upper end opened into the posterior wall of the trachea. In one case in which exact measurements were taken, the aperture in the wall of the trachea was $\frac{3}{4}$ inch above the level of the atresia; the upper part of the œsophagus measured $1 \frac{1}{2}$ inches, the lower part 2 inches. In the sixth case the notes simply state that a complete atresia existed 3 inches from the mouth; the whole region was then removed en bloc for further dissection. Whether or not a communication with the trachea existed is not stated.

In only one case was there any further abnormality; this consisted of complete absence of the left kidney.

A considerable number of cases of congenital nesophageal atresia has been recorded. Von Reuss ${ }^{(1)}$ states that more than a hundred are on record, and Cautley(2) collected and published a list in 1917. A full bibliography of the subject is given by Heumann(3), who quoting Kreliter and Vieillard, gives the percentage of cases with a communication between the trachea and lower portion of the œsophagus as between 87 and 92 .

Keith and Spicer(4) described three cases, and added a developmental explanation of the abnormality. Normally the posterior rim of the opening from the primitive osophagus formed by the evagination of the lung bud, grows forward and thus separates the œsophagus from the trachea, becoming the tracheo-œsophageal septum. Were this septum to grow irregularly, leaving a gap in its growth, a communication between the trachea and œsophagus would result. Moreover, if the part of such a septum anterior to the gap were to commence growing obliquely forwards and ventralwards from the dorsal wall of the œsophagus, the œsophagus would become divided into two portions.

The three figures demonstrate these points. Figure 1 shows the normal formation of the tracheo-œsophageal septum. Figure 2 shows the formation of a gap in the septum. Figure 3 shows the abnormal origin of the cephalic portion of the divided septum.

The treatment of this condition is practically hopeless. Gastrostomy was performed on two of the six cases, and other cases in the literature have undergone this operation without success. Since there is in the vast majority of instances a tracheo-øsophageal communication, if food in the stomach is vomited, it will immediately be precipitated into the trachea, and aspiration 

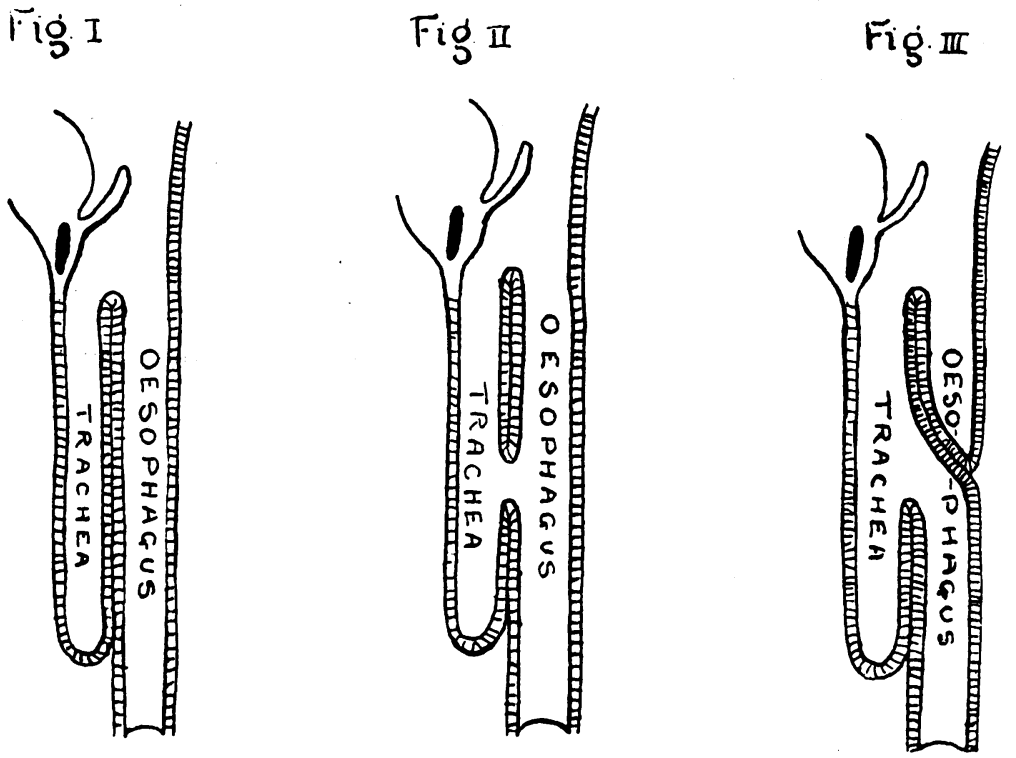

pneumonia will result. Richter(5) has attempted to overcome this in two cases, by crushing and ligaturing the tracheo-œsophagea! communication, and then performing gastrostomy. Both cases proved fatal.

Presumptuous as it must seem for one unskilled in surgery to offer a suggestion in the treatment of these cases, my excuse lies in a consideration of the mortality of the condition. It should be possible to open the stomach and pass a soft catheter through the cardiac orifice, through the tracheoœsophageal communication into the trachea, and ultimately out through the mouth. A fan-shaped lower end to the tube should prevent its slippinir back out of the stomach into the cesophagus, and at the same time prevent the vomiting of food alongside the tube. If the nutrition of the infant could be maintained and improved by this means, later operations to correct the mal-development might be more hopefully undertaken.

In the two cases of partial stenosis of the œsophagus, death occurred at the age of 3 and 4 years. Vomiting almost immediately after swallowing food had occurred on ard if since birth, in bouts lasting about a week with an interval of about a month. During attacks, constipation was severe. Post mortem examination showed a fibrous stenosis in the lower third of the œsophagus, through which probes could be easily passed. These cases showed no communication between the trachea and csophagus.

\section{DUODENUM.}

No case was found of congenital atresia at the pylorus. At this position atresia is rare, only four cases having been reported. The duodenum is, however, not so uncommon a situation, the position of the atresia being 
classified according to its relation to the bile papilla. In the two cases stated in the above list to be below the papilla, the actual site of the atresia was at the duodeno-jejunal junction.

The average length of life in the six cases was 12 days, the limits being 4 and 21 days. But the length of life gave no indication to the position of obstruction, for the cases living for 21 days showed atresia at or above the entrance of the bile-duct.

The symptoms of forcible vomiting dating from the first taking of food, visible peristalsis passing from left to right ac:oss the epigastrium, small motions consisting only of meconium, and progressive wasting, were recorded in most of the cases. In addition, in both cases in which the atres:a was below the entrance of the common bile-duct, bile was found in the vomited material. In one case with atresia at the level of the bile papilla, the romit was also noted to be dark brown, and at autopsy bile was present in the duodenum both above and below the obstruction. The explanation of this is that the bile-duct probably had two openings into the duodenum on each side of the atresia. The vomit contained no bile in the two examples of atresia above the bile papilla.

In both cases where the atresia was below the bile papilla, the infant was jaundiced, but the post mortem findings in these cases suggestied that jaundice need not necessarily be present. Those cases which lived beyond the first week showed a remarkable degree of dilatation of the stomach and proximal portion of the duodenum, the pyloric ring being also so dilated as to render it somewhat difficult to identify. These cases would probably vomit all the bile that reached the duodenum, and so diminish the liability to jaundice.

The precise nature of the obstruction found post mortem varied. In most instances, the atresia appeared to consist of a short fibrous ring, but in one case the two portions of ducdenum were comrletely separated, the blind end of the peripheral portion lying buried in the head of the pancreas. In another case a complete obstruction was prodiced by the fus: on at one point of the mucosa, the other coats of the duodem leing inaffected. In one case, in addition to the atresia, complete transposition of the viscera was found, associated with absence of the spleen, or of any accessary spleen tissue.

There were two examples of incomplete stcnosis of the duodenum at the level of the entrance of the commen bile-dlict. In ore, the child lived for three weeks and at autopsy a thin trok'c of water could be passed through the stenosis. The other child lived to the age of 21 months. At the post mortem, a fine probe could be passed with diffenlty through the constriction

\section{Small and Iarge Intestine.}

These are taken together, because in two cases atresia was found in both sections of the intestine. 
Although one case reached the age of nineteen days, the average length of life was six days. Two died almost at once after admission to hospital. The remainder survived long enough for surgical treatment to be essayed, but except in one case of atresia of the rectum, death followed laparotomy within 36 hours.

The symptoms in these cases consisted of vomiting commencing with the first taking of food, absolute constipation except for the passage of a small amount cf meconium, and distension of the abdomen. Usually visible intestinal peristalsis was noted, the intestines standing out across the abdomen in the typical step-ladder pattern. Vcmiting did not occur in two cases; in one of these the atresia occurred in the sigmoid colon, in the other the intestine was patent as far as the middle of the rectum, where it te minated blindly.

The findings at autopsy varied. In eight cases, a portion of the small intestine was represented by a fibrous cord, which varied in length from a quarter of an inch to several feet. In one of these, the upper half of the small intestine was completely impervious, whilst below this level as far as the rectum, the intestine was uniformly small, with a minute lumen.

In six cases distinct gaps occurred in the continuity of the bowel. In one of these, no less than three gaps were fo:n. In another a gap was followed three inches lower by a fibrous :.tresia. The intervening portion of small intestine had formed a volvulus. In a third, the blind end of the distal length of small intestine was adherent to a mesenteric cyst as large as a hen's egg.

In one instance, there was complete transposition of the viscera.

Finally, two examples of partial stenosis were found, both affecting the lower third of the small intestine and the whole of the colon. In these the bowel in the stenosed portion was about as large in circumference as a lead pencil; the lumen was very narrow, and filled with a white detritus. Neither of these infants lived beyond the first week of life.

Various theories have been advanced to explain these conditions, but no theory will fit all the cases. It has been supposed that fœtal peritonitis might be a cause, but further evidence of previous peritonitis is not usually to be found. Another view is that at the various points of embryological importance in the intestinal tract, errors in development have occurred. Sich points would be the origin of the hepatic and pancreatic buds, or near the vitello intestinal duct, but some of the cases involve a greater length of bowel than this theory could explain. while in others, the atresia does not seem to have occurred at points of particular embryological interest. Thus in one infant the small intestine terminated 18 inches from the pylorus; in another three feet from the duodeno-jejunal junction.

It has been shown that in the duodenum, and probably throughout the intestines, there takes place during development an epithelial proliferation 
sufficient to block the original lumen. This proliferation is later removed, but should the condition persist in places, atresia would probably result. This will explain certain cases. Others may result from intra-uterine misadventure, such as volvulus or intussusception.

The treatment of congenital intestinal atresia lies in surgical measures, although so far the results have not been encouraging.

I wish to express my thanks to the Medical Staff of the Hospital for Sick Children, Great Ormond Street, for permission to make use of the hospital records.

\section{REFERENCES.}

1. Von Reuss, A. R., "The Diseases of the Newborn," London, 1921, 251 et seq.

2. Cautley, E., Brit. Journ. Child. Dis., 1917, XLV, 1.

3. Heumann, J., Abt's Pediatrics, Philadelphia, III, 406, et seq.

4. Keith, A., and Spicer, J. E., Jour. Anat. and Phys., London, 1907, XLI, 52.

5. Richter, H. M., Surg. Gynop. and Obst., Chicago, 1913, XVII, 397. 